\title{
Utilisation patterns of helpline and Web chat services among gamblers in Singapore
}

\author{
Pezhummoottil Vasudevan Nair Asharani ${ }^{1}$, PhD, Syidda Amron ${ }^{1}$, BSc(Hons), Raymond Swee Khoon $\mathrm{Ng}^{1}$, BSc(Hons), \\ Sunil Varghese ${ }^{1}$, Msw, Christopher Cheng Soon $\underline{\text { Cheok }}^{2}$, MB, MMed
}

\begin{abstract}
We evaluated the utilisation of a helpline and Web chat system by the public for gambling-related services in Singapore over a period of 12 months. The profile of callers, call characteristics and actions taken were descriptively analysed using aggregate data. The majority of helpline calls and Web chats were from gamblers aged $40-49$ years (23.3\%, $n=644)$. Gamblers made $85.4 \%(n=8,010)$ of the calls to the helpline and $73.3 \%(n=546)$ of the Web chats. About four-fifths of the gamblers were Chinese $(79.5 \%, n=6,381)$ and employed full time $(79.9 \%, n=4,125)$. Table games $(67.6 \%, n=2,605)$ were the most popular gambling activity reported by callers, $55.8 \%$ of which involved local casinos. Enquiries were mostly casino related $(92.4 \%, n=5,739)$. Approximately 1,827 calls were received per month during the study period and 185 referrals were made to the clinic, $80.5 \%$ of whom sought treatment.
\end{abstract}

Keywords: helpline, phone services, Web chat

\section{INTRODUCTION}

Gambling, a common recreational activity, can become an addiction for individuals and bring about negative consequences. Among probable pathological gamblers in Singapore, the proportion of frequent gamblers increased by $15 \%$ in 2014 compared to 2011.(1) The number of legal orders relating to casino exclusions, such as self-exclusion orders in which individuals bar themselves from entering local casinos, increased from 276,516 in December 2016 to 285,024 in March 2017. ${ }^{(2)}$ Despite increases in policy and legal regulations, problem gambling may continue to be a challenge.

Several countries have successfully employed helpline services to engage gamblers and their caregivers. ${ }^{(3-6)}$ Profiling of Italian gambling helplines showed that most callers preferred helplines for counselling over email and chat services. ${ }^{(7)}$ Conversely, Rodda and Lubman analysed the utilisation of an Australian gambling management service and noted that gamblers preferred chat services over email.(8) Another study evaluating data from gambling helplines identified age-specific clinical characteristics of callers and their need for tailored treatment. ${ }^{(5)}$ These reports demonstrated the utility and acceptance of such interventions by the public.

The National Council on Problem Gambling, Singapore, introduced its helpline in 2008 and Web chat system in 2014, underpinning a continuing effort to protect Singapore residents from the negative consequences of gambling. This platform facilitates access to healthcare by disseminating necessary information, educating the public and providing psychological support to those who face geographical and societal restrictions. Examining the utilisation of such services is useful for organisations to understand the needs of callers and call characteristics and, in turn, help them to use resources wisely. Comparisons with international research can also be performed to improve the quality of care in Singapore.

\section{UTILISATION OF HELPLINE AND WEB CHAT SERVICES}

We conducted a retrospective study with approval from the National Healthcare Group Domain Specific Review Board and the National Council on Problem Gambling. 12 months of calls and chats received by the helpline and Web chat were descriptively analysed using Microsoft Excel, with the intent of understanding service utilisation to ensure efficient resource distribution. Data was then grouped under three categories: (a) profile of callers; (b) call characteristics; and (c) follow-up action.

\section{Profile of callers}

There were approximately 20,748 calls and 1,697 chats from July 2015 to June 2016. Among these, the reported data was the available aggregate data for individual variables. Approximately 9,376 telephone calls and 745 Web chats were recorded and stored in the helpline system. In terms of caller type, gamblers were predominant for both telephone calls $(85.4 \%, \mathrm{n}=8,010)$ and Web chats $(73.3 \%, \mathrm{n}=546)$.

Caller demographics were also recorded. Of the 13,524 callers whose genders were captured, the majority of the gamblers $(79.7 \%, \mathrm{n}=9,074)$ were male and most caregivers $(64.9 \%, n=1,391)$ were female. Additionally, 2,012 caregivergambler relationships were also recorded in the helpline system. Caregivers ( $n=2,012)$ comprised spouses $(26.4 \%)$, siblings $(21.8 \%)$, parents $(20.2 \%)$ and children $(19.7 \%)$. Grandparents, cousins and other family members of the gambler were classified as others (11.9\%). The 2,769 gamblers who provided their ages belonged to the age groups of $40-49$ years (23.3\%), 30-39 years

${ }^{1}$ National Addictions Management Service (NAMS), ${ }^{2}$ Department of General and Forensic Psychiatry, Institute of Mental Health, Singapore

Correspondence: Dr Asharani Pezhummoottil Vasudevan Nair, Assistant Manager for Research, National Addictions Management Service (NAMS), Institute of Mental Health, Buangkok Green Medical Park, 10 Buangkok View, Singapore 539747. Asharani_PEZHUMMOOTTIL_VASUDEVAN_N@imh.com.sg 
Table I. Main and additional gambling activities.

\begin{tabular}{|lll|}
\hline \multirow{2}{*}{ Gambling activity } & \multicolumn{2}{c|}{ No. (\%) } \\
\cline { 2 - 3 } & Main & Additional \\
\hline Lottery & $295(7.6)$ & $47(1.2)$ \\
\hline Singapore Sweep & 23.7 & 27.7 \\
\hline $4 D$ & 40.7 & 36.2 \\
\hline TOTO & 57.8 & 36.2 \\
\hline Horse betting & $64(1.7)$ & $15(0.4)$ \\
\hline Turf Club & 57.8 & 53.3 \\
\hline Unregistered/others & 42.2 & 46.7 \\
\hline Sports betting & $239(6.2)$ & $23(0.6)$ \\
\hline Singapore Pools & 55.2 & 56.5 \\
\hline Unregistered & 44.8 & 43.5 \\
\hline Jackpot & $648(16.8)$ & $35(0.9)$ \\
\hline Local casino & 52.9 & 37.1 \\
\hline Overseas casino & 9.6 & 11.4 \\
\hline Clubs (local) & 11.1 & 14.3 \\
\hline Cruise & 9.0 & 14.3 \\
\hline Unregistered & 8.6 & 11.4 \\
\hline Remote & 8.8 & 11.4 \\
\hline Table games & $2,605(67.6)$ & $10(0.26)$ \\
\hline Local casino & 55.8 & 20.0 \\
\hline Overseas casino & 11.1 & 20.0 \\
\hline Cruise & 11.0 & 20.0 \\
\hline Unregistered & 11.1 & 20.0 \\
\hline Remote & 11.0 & 20.0 \\
\hline
\end{tabular}

Values for individual gambling activities are presented as a percentage of the total.

(22.4\%), 50-59 years (18.9\%), 21-29 years (16.5\%), $\geq 60$ years $(10.0 \%)$ and $\leq 20$ years $(8.9 \%)$. Among the 116 caregivers, $26.7 \%$ were aged $21-29$ years, followed by those aged $\geq 60$ years (21.6\%), $40-49$ years (19.8\%), 50-59 years $(15.5 \%), 30-39$ years $(11.2 \%)$ and $\leq 20$ years $(5.2 \%)$.

Singaporeans and permanent residents $(n=9,536)$ dominated the caller group regardless of caller type, comprising $67.1 \%$ of gamblers and $93.8 \%$ of caregivers, compared to $32.9 \%$ and $6.2 \%$ from foreigners $(n=3,863)$, respectively. Gambler callers consisted of Chinese (79.5\%, $n=6,381)$, Malay $(9.0 \%, n=719)$, Indian $(8.3 \%, \mathrm{n}=667)$ and other ethnicities $(3.2 \%, \mathrm{n}=258)$, while caregivers were of similar ethnic proportions, consisting of Chinese $(79.0 \%, \mathrm{n}=1,659)$, Malay $(8.0 \%, \mathrm{n}=168)$, Indian $(9.3 \%, n=195)$ and other ethnicities $(3.7 \%, n=78)$. A large proportion of gambler callers were full-time employees $(79.9 \%$, $\mathrm{n}=4,125)$, while $8.4 \%(\mathrm{n}=435)$ were unemployed. Students contributed to $4.6 \%(n=239)$ of the total calls, $2.8 \%(n=146)$, were homemakers and retirees, $1.9 \%(\mathrm{n}=99)$ were self-employed and $2.3 \%(n=118)$ were part-time employees.

Table I shows the main and additional gambling activities of the gamblers. Table games were the most popular $(67.6 \%)$ primary gambling activity, among which $55.8 \%$ involved local casinos. Overseas casinos, cruises, unregistered services and remote games comprised about $11.0 \%$ each of the other activities. Jackpot $(16.8 \%)$ was the second most popular activity, following the same trend as table games with $52.9 \%$ of callers playing it in local casinos. The lottery $(7.6 \%)$ was the third most reported gambling activity, with TOTO (57.8\%) being the most played, followed by 4D (40.7\%) and Singapore Sweep (23.7\%). Sports betting $(6.2 \%)$ was done through Singapore Pools (55.2\%) and unregistered agencies or other modes (44.8\%). Similarly, 57.8\% used Turf Club portals for horse betting, while $42.2 \%$ resorted to unregistered services or other modes.

Regarding classification of requests, of the 6,212 calls recorded, 92.4\% were casino-related queries $(n=5,739)$ and $5.3 \%(\mathrm{n}=331)$ were requests for problem gambling counselling; $1.8 \%(n=110)$ of callers also requested for financial counselling and $0.5 \%(\mathrm{n}=32)$ for legal aid. A detailed descriptive analysis of casino-related queries was done. Among those who enquired about casino-related issues, $81.0 \%(n=4,651)$ of calls were for matters related to self-exclusion (including exclusion and revocation of exclusion). Self-exclusion is a voluntary application that prohibits a person from entering casinos. Enquiries by family members and gamblers about family exclusion orders formed $11.7 \%(n=664)$ of the calls. $3.5 \%(n=201)$ were regarding automatic or non-automatic exclusions, which are imposed by the law on bankrupts, recipients of government financial aid, or those in Housing and Development Board rental arrears of more than six months. Family visit limits constituted another $0.3 \%$ ( $n=18)$, non-casino exclusions $0.9 \%(n=49)$, and other visit limit-related queries $2.7 \%(n=156)$ of the calls.

\section{Call characteristics}

Call characteristics were described using call volume (i.e. number of calls received) and the time each call was attended to. On average, 1,827 calls were received each month. Approximately $95 \%$ of calls were attended to. Although call volume was distributed evenly throughout the study period, the months of February, March and May received the highest volume of calls (Fig. 1a). The fewest calls were recorded during November, December and June, coinciding with the school holiday period. December also saw the lowest number of Web chats (Fig. 1b). Chat volume was otherwise consistent in the rest of the year. Overall, the para-counsellors engaged callers appropriately by attending to the majority of the calls. The call centre has three shifts: the day shift $(8.30 \mathrm{am}-6.00 \mathrm{pm})$, evening shift $(6.00 \mathrm{pm}-$ $10.00 \mathrm{pm})$ and midnight shift (10.00 pm-8.30 am). 80.6\% of gamblers $(n=6,456)$ and $74.8 \%$ of caregivers $(n=1,088)$ called between 8.30 am and 6.00 pm (Fig. 2a). Chat timings were more evenly dispersed, with $49.5 \%$ of gamblers $(n=270)$ contacting the day shift, $31.0 \%(n=169)$ the evening shift and $19.6 \%(n=107)$ the midnight shift. A similar trend was observed for caregivers at $51.3 \%(n=102), 30.7 \%(n=61)$ and $18.1 \%(n=36)$ for the day, evening and night shifts, respectively (Fig. 2b).

\section{Follow-up action}

Cases warranting medical or counselling support were referred to the National Addictions Management Clinic for further assessment. A total of 185 (21.7\%) gamblers were referred to the clinic. Of these referrals, $149(80.5 \%)$ gamblers registered 

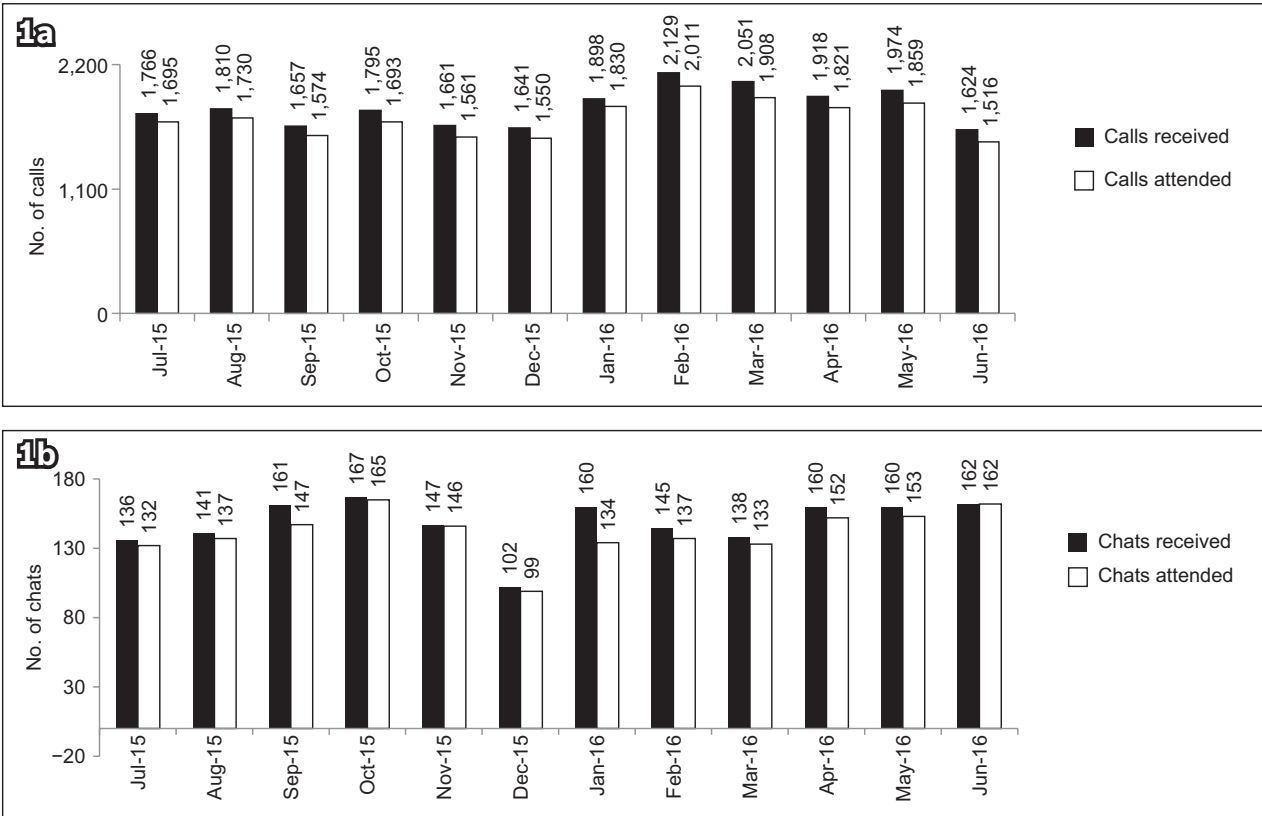

Fig. 1 Bar charts show (a) the number of calls; and (b) the volume of chats received and attended during the study period from July 2015 to June 2016.
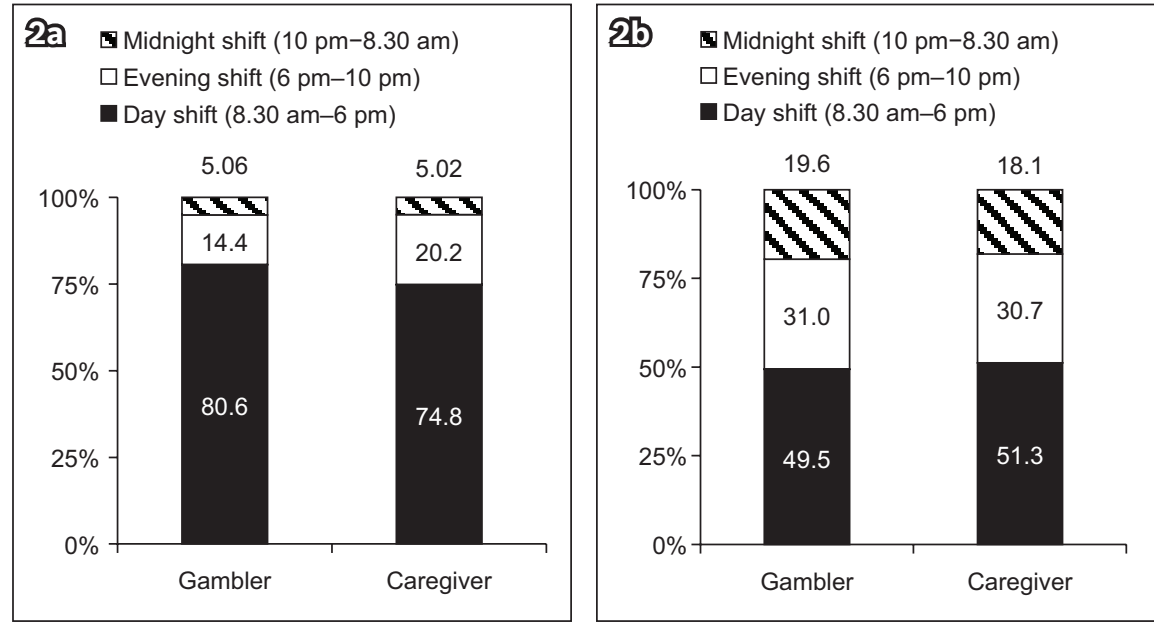

Fig. 2 Bar charts show (a) the percentage of calls received; (b) the volume of Web chats during each shift.

and sought treatment at the clinic, indicating that the referral process was effective.

\section{DISCUSSION}

Gambling-specific call centres act as extensions of addiction services, providing members of the public with information and linking them to government aid and clinic referrals. Within the year-long study period, a remarkable 20,748 calls, averaging 1,827 per month, were recorded at the call centre, demonstrating public awareness of such extended healthcare services. The primary goal of the call centre is to encourage help seeking among gamblers, thereby mitigating the harmful effects of the disorder, and to provide insight into the characteristics of callers at a stage where intervention is ideal.

A considerable proportion of our callers were caregivers. Gamblers often encounter financial issues due to excessive gambling, which strains their family relationships. ${ }^{(9-11)}$ Family members also face the burden of the habit and may reach out for help. Remote counselling is a useful resource for caregivers and gamblers to understand their problems, gather more information and make informed decisions regarding treatment seeking. In accordance with our report, Rush et al ${ }^{(12)}$ noticed that $22.8 \%$ of help-seeking clients in specialised centres were caregivers of gamblers. We also noted that the gamblers who reached out for help were mostly male, a statistic that matches the demographic of the treatment-seeking group in the clinic and in the international literature. ${ }^{(13,14)}$

Requests made to the call centre primarily included casino-related matters, especially requests for self-exclusion or revocations of existing self-exclusions. Self-exclusion imparts a perception of control among those who gamble uncontrollably, acting as a means of reducing gambling activity and providing a gateway to access treatment. ${ }^{(15-17)}$ It can be assumed that gamblers retain some insight, as evidenced by their requests for information regarding the self-exclusion service.

Contrary to the international data, ${ }^{(7)}$ callers reported a preference for strategy-based games such as table games and 
jackpot, mainly at local casinos. This discrepancy can be attributed to the fact that the dominant age groups cited in the literature differed from those in our study (older adults vs. young), which is examined by Potenza et al. ${ }^{(5)}$

Overall, the helpline services were well utilised by the public, as shown by call volumes. On average, the helpline's para-counsellors received 1,827 calls and 148 chats per month, of which an average of 1,729 calls and 141 chats were attended to. The majority of these calls were received during the day shift (8.00 am-6.00 pm), the busiest time for the call centre. Web chat services showed a more even call distribution, with more chats received during the evening shift (6.00 pm-10.00 pm), which could be the time when people commute after office hours. This is supported by the demographic data, in which $79.9 \%$ of callers were employed full-time. Furthermore, $21.7 \%$ of referrals to the clinic were for gambling, while the rest were referrals to other agencies or services. Interestingly, $80.5 \%$ of the referrals turned up at the clinic, implying that the helpline is useful in promoting treatment-seeking behaviour for gamblers who are otherwise not committed to seeking treatment.

Our datasets could not be individualised, which was a limitation of the data collection process. These utilisation patterns could be better assessed and monitored if the data for each individual caller is diligently captured; making data capture fields mandatory is one option to achieve this. It would also be helpful to explore the types of requests by caregivers, especially spouses. These details would help the care provider to identify caregivers' treatment precipitators and understand the severity of family issues, considering that intimate partner violence is known to be common among gambling families. ${ }^{(18)}$

In conclusion, the call centres appeared to be a useful service heavily utilised by the public as a source of necessary information regarding gambling-related issues, legal aid and treatment. The aggregated data collected gave an overall profile of the callers and their needs, although it failed to show the characteristics of specific groups due to the aggregated nature of the data.

\section{ACKNOWLEDGEMENTS}

The authors thank Syawal Hussain, Contact Centre, Institute of Mental Health, and Tan June Wen, National Addictions Management Service, Institute of Mental Health, for their intellectual contributions during the active phase of this project. The call centre services are funded by the National Council on Problem Gambling, Ministry of Social and Family Development, Singapore. The authors have no financial conflicts of interest.

\section{REFERENCES}

1. National Council on Problem Gambling. Report of survey on participation in gambling activities among Singapore residents, 2014. Available at: https:// www.ncpg.org.sg/en/pdf/2014\%20NCPG\%20Gambling\%20Participation \%20 Survey_FINAL.pdf. Accessed March 27, 2019.

2. National Council on Problem Gambling. Active casino exclusion and visit limit statistics. In: Update of Statistics by National Council on Problem Gambling [online]. Available at: https://www.ncpg.org.sg/en/pdf/Exclusion\%20and\%20 Visit\%20Limit\%20Statistics\%20for\%20Media\%20Release \%20(as\%20at\%20 30\%20June\%202017).pdf. Accessed March 27, 2019.

3. Ledgerwood DM, Steinberg MA, Wu R, Potenza MN. Self-reported gamblingrelated suicidality among gambling helpline callers. Psychol Addict Behav 2005; 19:175-83.

4. Griffiths M, Scarfe A, Bellringer P. The UK national telephone gambling helplineresults on the first year of operation. J Gambl Stud 1999; 15:83-90.

5. Potenza MN, Steinberg MA, Wu R, Rounsaville BJ, O'Malley SS. Characteristics of older adult problem gamblers calling a gambling helpline. J Gambl Stud 2006; 22:241-54.

6. Barry DT, Steinberg MA, Wu R, Potenza MN. Differences in characteristics of Asian American and white problem gamblers calling a gambling helpline. CNS Spectr 2009; 14:83-91.

7. Bastiani L, Fea M, Potente R, et al. National helpline for problem gambling: a profile of its users' characteristics. J Addict 2015; 2015:659731.

8. Rodda S, Lubman DI. Characteristics of gamblers using a national online counselling service for problem gambling. J Gambl Stud 2014; 30:277-89.

9. Shaw MC, Forbush KT, Schlinder J, Rosenman E, Black DW. The effect of pathological gambling on families, marriages, and children. CNS Spectr 2007; 12:615-22.

10. Lorenz VC, Shuttlesworth DE. The impact of pathological gambling on the spouse of the gambler. J Commun Psychol 1983; 11:67-76.

11. Muelleman RL, DenOtter T, Wadman MC, Tran TP, Anderson J. Problem gambling in the partner of the emergency department patient as a risk factor for intimate partner violence. J Emerg Med 2002; 23:307-12.

12. Rush B, Moxam RS, Urbanoski KA. Characteristics of people seeking help from specialized programs for the treatment of problem gambling in Ontario. J Gambl Issues [online] 2002. Available at: http://jgi.camh.net/index.php/jgi/ article/view/3598/3558. Accessed March 27, 2019.

13. Heater J, Patton D. Gender differences in problem gambling behaviour from help-line callers. J Gambl Issues [online] 2006. Available at: http://jgi.camh. net/index.php/jgi/article/view/3723/3683. Accessed March 27, 2019.

14. Potenza MN, Steinberg MA, McLaughlin SD, et al. Gender-related differences in the characteristics of problem gamblers using a gambling helpline. Am J Psychiatry 2001; 158:1500-5.

15. Ladouceur R, Jacques C, Giroux I, Ferland F, Leblond J. Analysis of a casino's self-exclusion program. J Gambl Stud 2000; 16:453-60.

16. Hayer T, Meyer G. Internet self-exclusion: characteristics of self-excluded gamblers and preliminary evidence for its effectiveness. Int J Ment Health Addict 2011; 9:296-307.

17. Ladouceur R, Sylvain C, Gosselin P. Self-exclusion program: a longitudinal evaluation study. J Gambl Stud 2007; 23:85-94.

18. Korman LM, Collins J, Dutton D, et al. Problem gambling and intimate partner violence. J Gambl Stud 2008; 24:13-23. 